\title{
Unprotected Sexual Intercourse
}

National Cancer Institute

\section{Source}

National Cancer Institute. Unprotected Sexual Intercourse. NCI Thesaurus. Code C88146.

Sexual intercourse without the use of precautions to prevent conception or the transmission of sexually transmitted diseases. 